06

\title{
Электропроводность структур металл-диэлектрик-полупродник на основе сегнетоэлектрических пленок
}

\author{
() М.С. Афранасьев ${ }^{1}$, Е.И. Гольдман ${ }^{1}$, Г.В. Чучева ${ }^{1, \uparrow, ~ А . Э . ~ Н а б и е в ~}{ }^{2}$, Дж.И. Гусейнов ${ }^{2}$, Н.Ш. Алиев ${ }^{3}$ \\ ${ }^{1}$ Фрязинский филиал Института радиотехники и электроники им. В.А. Котельникова РАН \\ Фрязино, Россия \\ ${ }^{2}$ Азербайджанский государственный педагогический университет, \\ Баку, Азербайджан \\ ${ }^{3}$ Институт радиационных проблем НАН Азербайджана, \\ Баку, Азербайджан \\ ฯ E-mail: gvc@ms.ire.rssi.ru
}

Поступила в Редакцию 19 августа 2019 г.

В окончательной редакции 19 августа 2019 г.

Принята к публикации 19 августа 2019 г.

\begin{abstract}
Приводятся результаты экспериментальных исследований частотных и температурных зависимостей электропроводности структур металл-диэлектрик-полупроводник на основе сегнетоэлектрических пленок состава $\mathrm{Ba}_{0.8} \mathrm{Sr}_{0.2} \mathrm{TiO}_{3}$. Установлено, что в температурном интервале $290-400 \mathrm{~K}$ в диапазоне частот $25-10^{6} \mathrm{~Hz}$ проводимость подчиняется закону $\sigma \propto f^{0.76}$, характерному для прыжкового механизма переноса заряда по локализованным вблизи уровня ферми-состояниям. Оценены плотность этих состояний, среднее расстояние и время прыжков.
\end{abstract}

Ключевые слова: структуры металл-диэлектрик-полупроводник, сегнетоэлектрические пленки, твердые растворы титаната бария-стронция, проводимость по переменному току.

DOI: 10.21883/FTT.2020.01.48748.570

\section{1. Введение}

В настоящее время наблюдается бурный рост числа теоретических и экспериментальных исследований в области устройств СВЧ. Имеет место как модернизация и расширение применения ранее известных устройств с увеличением рабочих частот, так и внедрение новых устройств на основе достижений физики твердого тела и прогрессивной технологии. Одно из приоритетных направлений развития устройств СВЧ и элементов энергонезависимой памяти - это использование структур металл-диэлектрик-полупроводник (МДП) с сегнетоэлектрическими пленками в качестве изолирующих слоев [1]. Уникальные физические свойства сегнетоэлектрических материалов (в частности, высокая диэлектрическая проницаемость, изменяемая под действием внешнего электрического поля) позволяют создавать на основе МДП-структур фактически новый класс устройств хранения и обработки информации [2]. Энергонезависимые элементы памяти на основе сегнетоэлектрических материалов характеризуются низкими токами потребления, большим числом циклов записи, длительным временем и высокой надежностью хранения данных при воздействии внешних факторов. Перспективным видом сегнетокерамики для применения в СВЧ технике являются твердые растворы титаната бариястронция $\left(\mathrm{Ba}_{1-x} \mathrm{Sr}_{x} \mathrm{TiO}_{3}\right.$ или BSTO). В настоящее время BSTO керамика успешно используется в ускорительной технике: фазовращатели и переключатели большой мощности для схем питания линейных ускорителей, управ- ляемые ускорительные структуры с диэлектрическим заполнением. Твердые растворы $\mathrm{Ba}_{1-x} \mathrm{Sr}_{x} \mathrm{TiO}_{3}$ обладают сегнетоэлектрическими свойствами при комнатной температуре, и диэлектрическая постоянная тонких пленок, в отличие от объемного материала, остается достаточно высокой и практически неизменной в широком диапазоне температур. Среди твердых растворов BSTO состав $\mathrm{Ba}_{0.8} \mathrm{Sr}_{0.2} \mathrm{TiO}_{3}$ отличается наименьшим размытием структурного фазового перехода, что делает его наиболее удобным материалом для промышленного производства конденсаторов интегральных микросхем и другой микрои наносистемной техники.

Исследования электронных свойств сегнетоэлектрических пленок занимают в последние десятилетия одно из центральных мест в физике конденсированного состояния вещества. Изучение свойств керамики BSTO с целью совершенствования технологии изготовления материала с заданными характеристиками структур на его основе является весьма актуальной физической задачей. В работе [1] исследовалось влияние размера зерна на диэлектрические и сегнетоэлектрические свойства $\mathrm{Ba}_{0.8} \mathrm{Sr}_{0.2} \mathrm{TiO}_{3}$. Перестройка поляризации и других свойств сегнетоэлектрической керамики BSTO при изменении внешнего поля были количественно изучены с помощью микроволновых измерений [3]. Несмотря на то, что BSTO, благодаря своим уникальным свойствам, уже давно находит применение при создании носителей оптической информации, элементов фотонных технологий и радиоэлектроники [1], механизмы электропроводности в этом высокоомном материале детально не ис- 
следованы. Настоящая работа посвящена изучению процессов переноса заряда в сегнетоэлектрической пленке $\mathrm{Ba}_{0.8} \mathrm{Sr}_{0.2} \mathrm{TiO}_{3}$ в переменном электрическом поле.

\section{2. Материалы и методики эксперимента}

Для проведения исследований были изготовлены структуры металл-диэлектрик-полупроводник (МДП), представляющие собой кремниевую подложку, сегнетоэлектрическую пленку состава $\mathrm{Ba}_{0.8} \mathrm{Sr}_{0.2} \mathrm{TiO}_{3}$ и верхний электрод из никеля. Сегнетоэлектрический слой выращен методом высокочастотного реактивного распыления керамической мишени в атмосфере кислорода на установке ПЛАЗМА-50 СЭ по методике, представленной в работе [4]. Главная идея метода состоит в использовании низкотемпературной кислородной плазмы в качестве среды, где окислительный процесс при осаждении преобладает над восстановительным. Основным преимуществом метода является возможность напыления структурно-совершенных сегнетоэлектрических пленок с сохранением стехиометрии по кислороду. В качестве подложек использован кремний $p$-типа марки КДБ-20 с кристаллографической ориентацией [100]. Толщина подложек $200 \pm 2 \mu \mathrm{m}$. Контакты формировались электроннолучевым методом через теневую маску. В качестве материала омического контакта использовался никель. Площадь контактов составляла $2.7 \cdot 10^{-4} \mathrm{~cm}^{2}$, толщина $0.1 \mu \mathrm{m}$.

Изучение электропроводящих свойств МДП-структур велось с помощью цифрового измерителя импеданса E7-20 в широком диапазоне частот $\left(25-10^{6} \mathrm{~Hz}\right)$. Для опытов были изготовлены образцы из сегнетоэлектрических пленок $\mathrm{Ba}_{0.8} \mathrm{Sr}_{0.2} \mathrm{TiO}_{3}$ с толщиной $310 \pm 20 \mathrm{~nm}$ на кремниевых подложках в виде плоских конденсаторов [5]. Измерения проводились при постоянном падении напряжения на образце $1 \mathrm{~V}$.

\section{3. Результаты и обсуждение}

Рентгенодифракционное исследование показало, что для всех исследованных пленок наблюдалось параллельное расположение осей пленки и подложки в плоскости сопряжения, т. е. [100]BSTO $\|[100] p$-Si. На рис. 1 представлены температурные зависимости малосигнальной проводимости $\sigma(T)$ сегнетоэлектрических пленок $\mathrm{Ba}_{0.8} \mathrm{Sr}_{0.2} \mathrm{TiO}_{3}$ при различных частотах. В диапазоне частот $25-10^{6} \mathrm{~Hz}$ график $\lg \sigma-10^{3} / \mathrm{T}$ состоит из двух прямых с различными наклонами; из чего следует вывод, что электропроводность сегнетоэлектрических пленок $\mathrm{Ba}_{0.8} \mathrm{Sr}_{0.2} \mathrm{TiO}_{3}$ термоактивационным образом зависит от абсолютной температуры $T$ [6]. По наклонам этих зависимостей определены энергии активации $E$, их значения уменьшаются с ростом частоты $f$ : в низкотемпературной области - от 0.15 до $0.05 \mathrm{eV}$, a в высокотемпературной от 0.75 до $0.35 \mathrm{eV}$. Отметим,

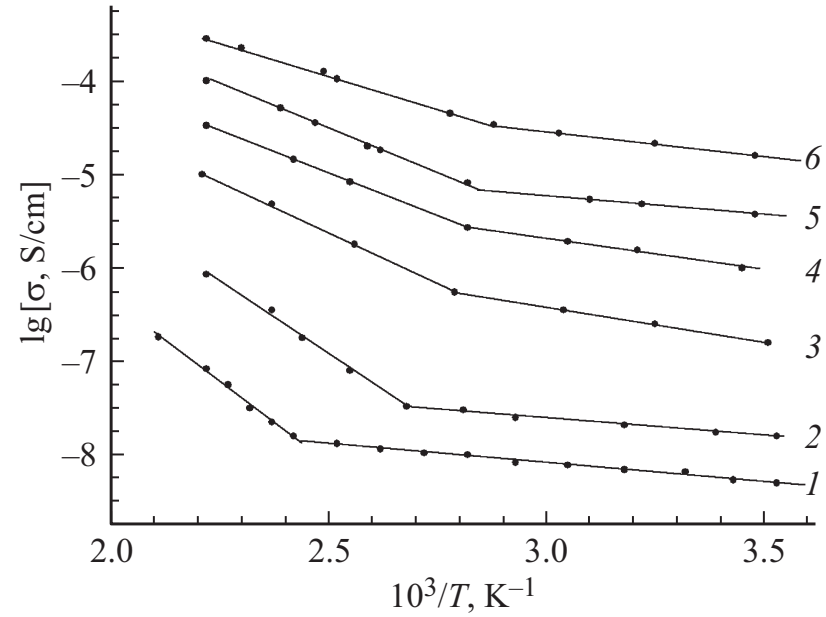

Рис. 1. Температурные зависимости электропроводности для структуры $\mathrm{Ba}_{08} \mathrm{Sr}_{0.2} \mathrm{TiO}_{3}$ при различных частотах: $1-25$, $2-10^{2}, 3-10^{3}, 4-10^{4}, 5-10^{5}, 6-10^{6} \mathrm{~Hz}$.

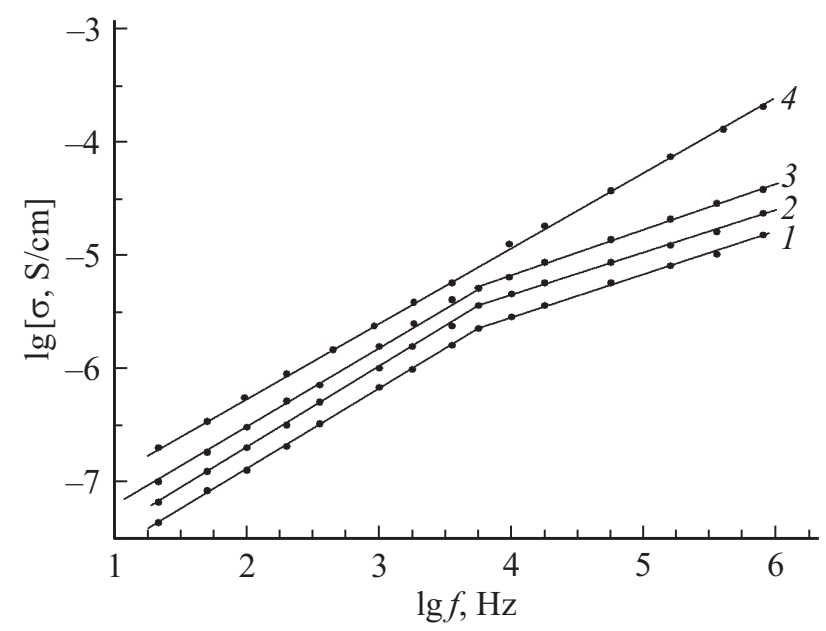

Рис. 2. Частотные зависимости электропроводности структуры $\mathrm{Ba}_{08} \mathrm{Sr}_{0.2} \mathrm{TiO}_{3}$ при различных температурах: 1 - 293, $2-373,3-423,4-453 \mathrm{~K}$.

что активационный характер (с постоянной энергией активации) поведения $\sigma$ вблизи комнатной температуры в диапазоне частот от $10^{4}$ до $10^{6} \mathrm{~Hz}$ нельзя считать доказанным, поскольку в этом интервале недостаточно экспериментальных данных (всего по три измерения на каждой частоте). Частотную зависимость энергии активации можно объяснить прыжковым механизмом электропроводности [7]. Из графиков $\sigma-f$ (см. рис. 2) следует, что экспериментальные данные хорошо описываются соотношением

$$
\sigma=A f^{s}
$$

где $A-$ постоянный коэффициент, характеризующий свойства исследованного образца, показатель степени $s$ при частотах ниже $10^{4} \mathrm{~Hz}$ равен 0.76 , а в диапазоне $10^{4}<f<10^{6} \mathrm{~Hz}$ уменьшается до 0.32. Отметим, что 
частотная зависимость проводимости (1) характерна для прыжкового механизма электропереноса [7].

В работе [7] для проводимости $\sigma$ получено выражение с неактивационным видом температурной зависимости:

$$
\sigma(T)=\frac{\Omega}{T} \exp \left(\frac{T}{T_{0}}\right)
$$

где $T_{0}$ - характеристическая температура, $\Omega$ - коэффициент пропорциональности. Согласно формуле (2), комбинация $\ln (\sigma T)$ должна линейно зависеть от температуры. На рис. 3 приведена экспериментальная зависимость $\ln (\sigma T)-T$ при разных частотах). Она оказывается прямолинейной, что противоречит активационному характеру, но подтверждает прыжковый механизм проводимости. В работах $[8,9]$ для частотной зависимости прыжковой проводимости получено следующее выражение:

$$
\sigma=\frac{\pi^{4} e^{2} k T N_{F}^{2}}{48 \alpha^{5}} f\left[\ln \left(\frac{v_{p h}}{2 \pi f}\right)\right]^{4},
$$

где $N_{F}$ - плотность локализованных состояний вблизи уровня Ферми, $k-$ постоянная Больцмана, $\alpha-$ постоянная пространственного затухания локализованного состояния электронов (для волновой функции используется представление $\Psi \propto e^{-\alpha r}, r-$ расстояние от центра локализации до точки наблюдения), $v_{p h}$ фононная частота, $e-$ элементарный заряд. Согласно выражению (3) проводимость зависит от частоты как $f\left[\ln \left(v_{p h} / f\right)\right]^{4}$, но при $f \ll v_{p h}\left(v_{p h} \approx 10^{12} \mathrm{~Hz}\right)$ член в квадратных скобках хорошо аппроксимируется зависимостью $f^{-0.2}$, что практически приводит к совпадению экспериментальной зависимости (1) с соотношением (3). С помощью формулы (3) для значений $\alpha=1.5 \mathrm{~nm}$ и $v_{p h}=10^{12} \mathrm{~Hz}$ из экспериментальной функции $\sigma(f)$ была определена плотность состояний на уровне Ферми $N_{F}=4.5 \cdot 10^{19} \mathrm{eV}^{-1} \cdot \mathrm{cm}^{-3}$.

$\mathrm{У}$ ряда исследованных образцов температурные зависимости проводимости ниже $400 \mathrm{~K}$ спрямлялись в

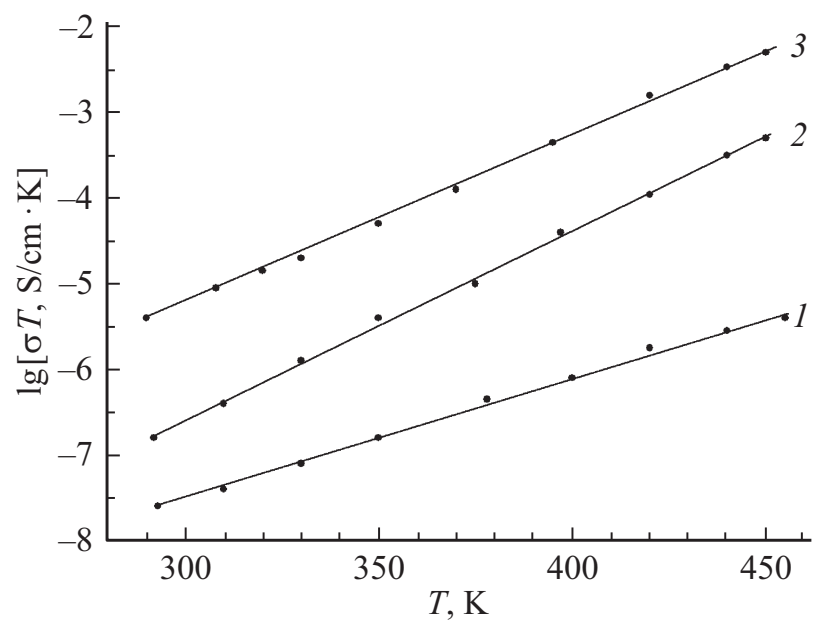

Рис. 3. Зависимость $\ln (T \sigma)-T$ пленок $\mathrm{Ba}_{08} \mathrm{Sr}_{0.2} \mathrm{TiO}_{3}$ при: $1-10^{4}, 2-10^{5}, 3-10^{6} \mathrm{~Hz}$.

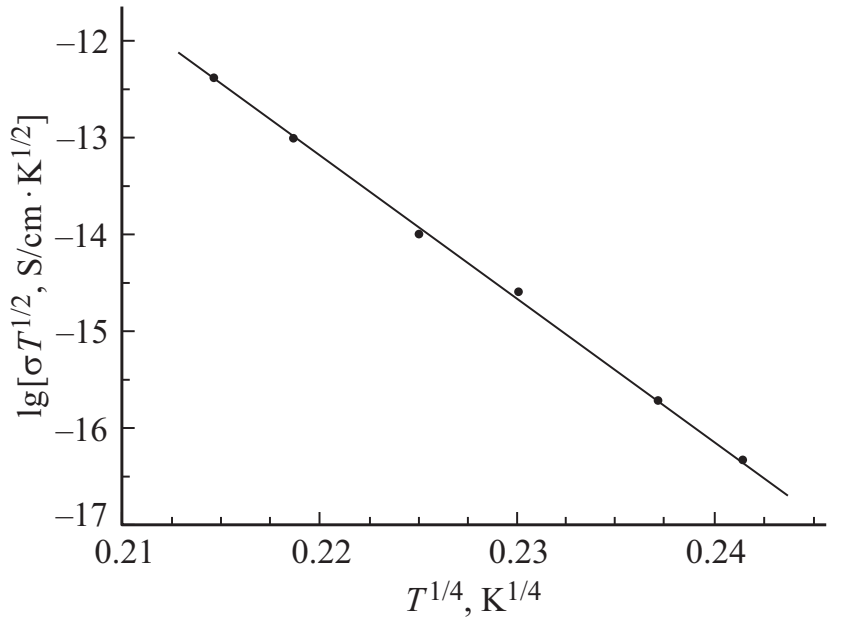

Рис. 4. Температурные зависимости электропроводности пленок $\mathrm{Ba}_{08} \mathrm{Sr}_{0.2} \mathrm{TiO}_{3}$ в координатах Мотта.

координатах Мотта $\lg \sigma-(1 / \mathrm{T})^{n}$ при $n=0.25$. Это свидетельствует о проводимости с переменной длиной прыжка, которая описывается соотношением $[10,11]$ :

$$
\sigma(T)=\sigma_{0} \exp \left[-\left(\frac{T_{0}}{T}\right)^{n}\right],
$$

где $\sigma_{0}-$ проводимость при $T \rightarrow \infty ; T_{0}=16 / N_{F} k \alpha^{3}-$ характерная температура; $n-$ показатель, характеризующий механизм проводимости с переменной энергией активации $(n=0.25$ для механизма Мотта [7] и $n=0.5$ для механизма Шкловского-Эфроса [10]). Экспериментальная температурная зависимость проводимости слоя $\mathrm{Ba}_{0.8} \mathrm{Sr}_{0.2} \mathrm{TiO}_{3}$ при $f=10^{4} \mathrm{~Hz}$ представлена на рис. 4 и указывает на преобладание механизма Мотта. Согласно теории прыжковой проводимости на переменном токе среднее расстояние прыжков $(R)$ определяется по следующей формуле $[8,9]$ :

$$
R=\frac{1}{2 \alpha} \ln \left(\frac{v_{p h}}{f}\right) .
$$

Для исследованных сегнетоэлектрических пленок значение $R$ составило $10 \mathrm{~nm}$. Связь между длиной и частотой прыжка задается выражением:

$$
\tau^{-1}=v_{p h} \exp (-2 \alpha R) .
$$

Откуда для среднего времени прыжков носителей заряда из одного локализованного состояния в другое получается: $\tau=10 \mathrm{~ns}$.

\section{4. Заключение}

Анализ полученных результатов позволяет заключить, что в исследованной температурной области проводимость сегнетоэлектрических пленок $\mathrm{Ba}_{0.8} \mathrm{Sr}_{0.2} \mathrm{TiO}_{3}$ осуществляется в основном по прыжковому механизму. 
Температурная и частотная зависимости электропроводности указывают на возможность реализации проводимости с переменной длиной прыжка по локализованным состояниям вблизи уровня Ферми.

\section{Финансирование работы}

Работа выполнена в рамках государственного задания.

\section{Конфликт интересов}

Авторы заявляют, что у них нет конфликта интересов.

\section{Список литературы}

[1] V.R. Mudinepalli, L. Feng, W.-C. Lin., B.S. Murty. J. Adv. Ceram. 4, 46 (2015).

[2] К.А. Воротилов, В.М. Мухортов, А.С. Сигов. Интегрированные сегнетоэлектрические устройства / Под ред. А.С. Сигова. Энергоатомиздат, М. (2011). 175 с.

[3] T. Teranishi, T. Sogabe, H. Hayashi, A. Kishimoto, K. Fujimori. Jpn. J. Appl. Phys. 52, 09KF06-1 (2013).

[4] М.С. Афанасьев, А.И. Левашова, С.А. Левашов, В.Г. Нарышкина, Г.В. Чучева, А.Э. Набиев. Соврем. информ. электрон. технологии 2, 128 (2014).

[5] М.С. Афанасьев, А.Э. Набиев, Г.В. Чучева. ФТТ 57, 1354 (2015).

[6] Ю.М. Поплавко, Л.П. Переверзева, И.П. Раевский. Физика активных диэлектриков. Изд-во Южного федерального ун-та. Ростов н/Д. (2009). 479 с.

[7] Н. Мотт, Э. Дэвис. Электронные процессы в некристаллических веществах. Мир, М. (1982). 664 с.

[8] M. Pollak. Philos Mag. 23, 519 (1971).

[9] M. Pollak. Tp. VI междунар. конф. по аморфным и жидким полупроводникам. Ленинград (18-24 ноября 1975) Наука, Л. (1976). С. 79.

[10] Б.И. Шкловский, А.Л. Эфрос. Электронные свойства легированных полупроводников. Наука, М. (1979). 416 с.

[11] A.L. Efros, B.I. Shklovski. Phys. Status Solidi B 76, 475 (1976).

Редактор К.В. Емцев 